\title{
Merchants Application Study of Consumption Value-Added Model
}

\author{
Hai-Sen Wang, Liang-Hui Zhao \\ School of Economy and Management, Wuyi University, Jiangmen, China \\ E-mail: 18765828522@126.com,18765828522@126.com
}

\begin{abstract}
Consumption capitalization theory market applications are collectively referred to as consumption valueadded model, the number of merchant uses consumption value-added model application gradually increase, attracting more and more consumer attention, this paper uses SWOT analysis method, analyzing advantages and disadvantages and opportunities and threats of business model, to choose consumption value-added model for merchants, carried forward feasible suggestions related, promote the development of businesses.
\end{abstract}

Keywords-consume capital; consumption value-added model; business application

\section{INTRODUCTION}

Consumption capitalization theory core is to extend consumption to the field of production and management. When consumers buy merchant's products, manufacturers and merchants should regard consumers as the investors of the procurement of products, and according to certain time interval, to a certain proportion of corporate profits to return to the consumer. At this point, the consumer buying behavior, is no longer a pure consumer, the consumer behavior became involved in the business investment behavior at the same time. Hence, consumers become investors, consumption is converted into capital. Consumption of das kapital, introduce the concept of consumption investment, along with the development of the market, there are more and more application of consumption capital business model. Yunlian-hui, intergrowth system platform, dick alliance, jin-ma, cover network hit in succession, and so on , many patterns play banner with spending money to make money, and return all consumption, consumption endowment, even disturb the market, let the consumer love them.

In China's economic downward trend, many enterprise survivals are difficult. Than lower consumption, consumption in China has been sluggish in recent years, the ratio of consumption fall from $46.7 \%$ in 1999 to $37.3 \%$ in 2013 (see in 2014, China statistical yearbook), consumption capital put forward that some Internet businesses find a new business model, and a variety of business is profitable to offer consumers consumption value-added model platform allows businesses hard choices.

Consumption capital since 2006, there have been many "consumption capital banner business model, after eliminating the baptism of the market, most have no way to put theory into practice, even in secret illegal fund raising, damage the business reputation, lost trust of consumers members $(1,2)$. In low current consumption and the country has to promote the development of consumption to promote today, for merchants consumption value-added application platform is inevitable, the government is also seeking an mutual benefit businesses and consumers on both sides of the business model, to determine the consumption mode of application of das kapital, obtain new development space and the development of energy, the merchant has important and far-reaching significance.

\section{BUSINESS APPLICATION CONSUMPTION VALUE-ADDED MODEL OF SWOT ANALYSIS}

\section{A. The Advantage}

First, the dealer is indispensable. The core of the consumption of das kapital, consumption extends to the production and business areas, when consumers buy their products, manufacturers and business enterprise should regard consumers purchase as the investment of the product, the consumer buying behavior at the same time has become a savings behavior and participate in business investment behavior. Any consumption value-added platform must have the manufacturer and the addition of business enterprise to operate.

Second, merchants have the option. Consumption of das kapital market application is still in its emerging stage, the marketing is difficult, and it takes a while for consumers to accept. Consumption value-added platform on the market very much, for businesses to choose is more, the chance of a successful businessman when selecting cooperation can strive for more discount and the sovereignty, realization of entity and the Internet, occupy the initiative.

\section{B. The Disadvantages}

First, business information is less. In market economy activities, all kinds of staff there are differences between the understanding of the relevant information ; Master information is sufficient staff, often in a more advantageous position, and poor information of personnel, are at a comparative disadvantage. There are a large number of consumption value-added model on the market, merchants can't understand the actual situation of consumption value mode, under the condition of asymmetric information is easy to make the wrong decision, caused economic losses. Consumption value-added model given preferential policies will falter, let businesses have no choice, thereby bungle opportunity. 
Second, the business profit is not high. Measure the industry average profit margin according to the state administration of taxation, commodity circulation industry was $3 \%$, tourism catering services was $9 \%$, high value-added model of platform in standard parts consumption, businesses cannot afford. Yun-lian-hui latform for merchants trading success pay $16 \%$ turnover, low profit industry cannot enter, even through the price means it is difficult to maintain life [3].

Third, crease operating costs. Era of a buyer's market, the businessman in a relatively weak position, the discount has been difficult to attract the interest of consumers, and because the buyers and sellers of the opposites, merchants discounts consumers don't buy it, all in the name of preferential consumer consumption value-added platform, merchants can only from consumption increment mode selection of one or more of the following, increase operating costs.

\section{The Opportunity}

First, encourages the development of new economy. For China to break through the middle-income trap, and on the key step is to create a new growth point of modernization and the change of consumption will be important economic trend in the future. State encourages the development of new economy, any consumption value-added model is not in violation of the rule of law can survive in the market environment, businesses can take advantage of the Internet tools, for their benefit, for the welfare of consumers, promote the development of the economy.

Second, create business brand image. A buyer's market, consumption value-added model can attract consumers' attention, easier to get consumers certainly, use consumption value-added mode can create awareness of the dealer, as consumer welfare businesses brand image, to win the trust of consumers.

Third, cater to consumer demand. Time has come for a third industrial revolution, the trend of The Times development determines the businessmen must consider, from the consumer oneself follow the progressive era, in response to consumer demand is one of the biggest winning quality, consumption value mode, in the vanguard of the era, let businessman is in an impregnable position. Consumer's consumption concept has become increasingly mature, consumer groups gradually younger, for discount selective enhancement, traditional way of preferential and not very good to cater to the consumer.

Forth, attract consumer spending money. Consumption value-added model has great appeal to consumers, businesses use consumption value-added model can attract more consumers, to increase business turnover. Many consumption value-added platform with rebates, normal consumption, consumers can get the preferential price or rebates, such as cloud hui consumption all return, merchants and cloud united cooperation, after the success of the transaction, the cloud would return the total consumer spending every day and merchants league very 5,5 and a half years of time to return all of the consumer is equivalent to not spend money to buy the product [4].
Fifth, increase of the dealer. Affection for consumers will have a good business, self-conscious propaganda merchants, the others to increase business visibility. Alternate system to consumers is preferential investment reached 10000 points, to achieve life-long free medical care, reimbursement of medical expenses $40 \%$, consumers get from signing merchants integral, when consumers realize free medical care will promote the benefits of alternate system, at the same time established a good brand image in the consumer heart, form the word-of-mouth, helping to also increase business visibility.

Sixth, increase sales channel. Consumption value-added model aims to build an alliance of consumers and businesses, signing businesses can in the consumer value-added model independent build platform selling goods, without destroying the original sales channels and price system to broaden the original sales channels. Using and consumption value-added model of platform, upload the merchant's goods, contact more customers, also for the merchants set up a online information communication and sales platform.

\section{Threats}

First, the imperfect market regulation. Government regulation is always better than slow a beat, the market behavior of some essential for early unable to identify the pattern of raising funds illegally or pyramid selling, application and consumption of das kapital market has been in practice, the model is also varied, the good and bad are intermingled, the government has no unified standard to measure, businesses use no matter which kind of consumption value-added model of platform will have a very big risk.

Second, the investment risk. Consumption is the biggest characteristic of das kapital mode for the welfare of the consumer, signing merchants may need to pay a membership fee or occupancy costs, once the consumption increment mode platform capital chain rupture, unable to realize the promise, use consumption value-added model of merchants upfront costs may also be treading water, increased operating costs and profit loss were unable to recover.

Third, damaged business credibility. Consumption valueadded model's commitment to consumers easily passed on to the businessman, once the platform collapse, commitment, credibility to the businessman consumers will doubt, decided that merchants deliberately did not live up to its promise, or think partnership cheat consumers, merchants and consumption value-added platform will greatly damage the merchant's integrity.

\section{ADVICE ABOUT APPLICATION CONSUMPTION VALUE- ADDED MODEL}

\section{A. Government Level}

First, strengthen communication, supervision. Strengthen the communication with vendors, fully understand the market dynamic, timely supervision, prevent the occurrence of illegal fund raising events, and even the growth of the pyramid retail group, to clear in time the market and improve the advance credit commitment, make credit classification 
regulation, afterwards and trustworthy joint incentive faithless joint punishment system, to expand the coverage of joint combination of punishment and incentive to promote administrative licensing, punishment information timely disclosure and whole flow of credit information sharing, build credit as the core of the new type of market supervision mechanism.

Second, strengthen the cooperation with the school. To strengthen the cooperation with schools, from the theoretical level demonstrates the feasibility of the model of valueadded business, early prevention is better than remediation. Set up a separate team, for a consumer value-added mode, makes promotion and innovation in the development of research model, and discusses the problems existing in the marketing, the good model to market faster.

\section{B. Merchants Level}

First, pay attention to the establishment of the brand. Any platform is a tool, the businessman to promotional tools. Merchant's focus should be on the quality of their products, good quality and consumer satisfaction, could get a brand effect. "Internet+" era, the subject or a commercial enterprise, electricity has brought people much convenience, too many preferential, too many choices, it is not in question, will be offline sales and Internet integration, place an order online and offline experiences, to satisfy the consumer, has become the mainstream of the market.

Second, actively join into consumer value-added platform .Consumption capital is put forward by professor Chen since 2006, most of the time used in raising funds illegally and the theoretical basis of pyramid selling, but the new economic mode of the development of The Times demand, consumer demand new economic model, only by following the development of The Times, don't complacent, limiting its growth. Consumption value-added platform catering to the voice of the consumer, but also to solve depressed consumption of weapons, requires businesses to actively participate in.

Third, fully understand. Consumption increment mode platform very much, need time to identify enterprise business cost a certain energy selection, understanding in condition of the platform, to understand the benefits for consumers and businesses is favorable, comprehensive consideration, weigh the benefits and gain and loss, full consideration to make decisions.

\section{CASE ANALysis}

\section{A. The Advantage of Merchants Signed Intergrowth System}

First, sign up for free, lifetime free use system, free to marketers' propaganda, increasing popularity. Second, provide free electric business platform, merchants can upload product, every single deal $1 \%$ fee (online mall: www.hsxt.cn). Third, attract a large number of customers for merchants. Signing businesses need to give $1 \%-30 \%$ discount to the customers, merchants to decide. Consumers are alternate card to sign up merchants consumption can get businessmen give preferential (in the form of points). Fourth, alternate card can solve survival endowment health care consumers, consumers have no trouble back at home, will increase consumption.

\section{B. The Disadvantage of Merchants Signed Intergrowth System}

First, increase the cost of operations. Human learning to use alternate system is necessary. Second, lower earnings. At least take out $1 \%$ of the price is favorable, will reduce the business profit $(5,6)$.

\section{SUMMARY}

In the process of China's economic growth and take-off, the changing pattern of global business and promote the world into the process of leading the era of "consumer", as "das kapital" consumption practice version of the consumer value-added business model, will become a leader. A new theory to be tested can be said that it is useless, ahead of its time, and some theory may have to wait until after several generations, to find its value. Practice is the sole criterion for testing truth consumption of das kapital describe theory is not only a kind of new economy, an enterprise new profit model, a consumer value-added implementation approach, or a solution to social problems. Consumption value-added model will be a future economics subject, at the same time, it will lead the future trend of the development of social economy.

\section{ACKNOWLEDGMENT}

This work is supported by the project of "Innovatively reinforce universities" plan of Guangdong Province Office of Education (Grant No.2014KTSCX130)(name of the project: economic and social system modeling and simulation), and the project of "twelfth five-year-plan" of Guangdong Philosophy and social science(Grant No.GD15XGL55)(name of the project: The action mechanism of newly-presented e-commerce marketing).

\section{REFERENCES}

[1] Xu-you liu, "Capitalization is a kind of consumption alienation theory", consumer economy, vol,1, pp, 1-2, Jan. 2009.

[2] Qi- xiang wen cool, "Look from the nature of consumer consumption capitalization of pseudo science", economist, vol.10, pp. 2-3, Oct. 2009.

[3] Wen-hai wu, "Introduction to application and practice of "das kapital" consumption. Journal of business culture", business culture, vol.10, pp. 1-2, Dec. 2014.

[4] Wei-yan cheng, "Consumption capitalization and implementation issues research", Journal of shenyang cadres, vol.4, p. 2, Apr 2015.

[5] Xiu-ping li, "Alternate system: the traditional consumption concept", China's reform., vol.10, pp. 1-2, Oct. 2015.

[6] Jian Cai, "Alternate system platform: dream or fantasy?", environment, vol. 1, pp. 1-2, Jan. 2009. 